\title{
POLICIAMENTO COMUNITÁRIO: A APROXIMAÇÃO DA POLÍCIA MILITAR JUNTO À COMUNIDADE
}

\author{
Luiz Ricardo dos Santos ${ }^{1}$
}

RESUMO: O presente trabalho de pesquisa e reflexão epistêmica tem, como objetivo, traçar apontamentos a respeito do papel da instituição pública Polícia Militar como organismo de aporte social em comunidades, tecendo aproximações em diversos polos que vão desde a de educação não formal, com ampliação de consciência cidadã, até aspectos que relacionam-se à dinâmica das interações sociais com as populações dos cenários onde estão inseridos. A pesquisa traz reflexões, sob o embasamento de referenciais bibliográficos que tratam da presença das forças de segurança em espaços de vulnerabilidades. $O$ artigo busca ampliar a ótica para este recorte territorial associando com os serviços prestados pelos servidores públicos do campo da segurança.

Palavras-chaves: Segurança. Comunidade. Comunicação. Organização Social. Polícia Militar.

\section{INTRODUÇÃO}

Ao tratar sobre o tema da Segurança Pública - objeto deste artigo -, traçamos várias possibilidades de decodificação a partir das ações de representação social que perpassam pela presença dos profissionais públicos deste setor de ação estratégica em comunidades. Para isso, este presente artigo irá buscar, ao longo de sua narrativa, referenciais e nortes reflexivos que mostram o quanto o campo do diálogo enriquecido pode ser essencial para a manutenção da ordem. Se faz necessário destacar, neste primeiro momento, que este campo reflexivo aporta-se no âmbito das representações sociais, ou seja, sobre como se configura a estrutura de imagem dos profissionais deste setor, em diálogo construído com as populações atendidas. Esta presente reflexão busca tecer estes apontamentos, que tratam da identidade da representação social. Organismos comunitários, públicos, que têm como objetivo

\footnotetext{
' Policial Militar na PMPR, Graduado em Administração de Empresas e Administração Rural, Pos graduado em Direito Ambiental, Direito Militar, Gestão em Logistica, Gestão Ambiental, Armazenagem de Grãos e Segurança Alimentar, Técnico em Segurança do Trabalho.
} 
cuidar dos cidadãos. Escola, espaços destinados à saúde, Polícia, e outros, são sempre observados como referência para a proteção e representação de uma comunidade.

E, aqui, faz-se necessário destacar o que é Policiamento Comunitário. Este termo ganhou força nos 70 e 8o, quando sistemas de policiamento, de diversos países passaram a mobilizar novos planejamentos estratégicos que saíssem do campo do policiamento ostensivo e pairasse, também, pelo campo da prevenção e das ações de parcerias com as comunidades. Neste sentido, deste recorte temporal até o presente momento, manifesta-se esta estratégia de forma muito mais acentuada, mobilizada e com novos instrumentais de participação da própria comunidade no âmbito das ações de segurança pública.

Ainda sobre o contexto do conceito, podemos tecer as seguintes considerações: or) no âmbito da representação social, o organismo público da segurança em um comunidade se apresenta em diversas territorialidades. Seja na presença física em bairros, na participação nas escolas da comunidade (com projetos de extensão, cidadania, orientações, palestras ou até mesmo em atividades de proteção, já que escolas são sempre alvos de criminosos para aliciamento de crianças e jovens). Mas, também, há uma presença macro neste espaço territorial da comunidade: os conselhos comunitários.

Eles são mobilizações de agrupamentos sociais que definem, em conjunto com diversos representantes de áreas múltiplas da comunidade, norteamentos para a boa condução e desenvolvimento social. Há diversos Conselhos (Saúde, Educação, Cultural, Meio Ambiente, Desenvolvimento Econômico, Segurança Pública, entre outros). Todos, contam com a contribuição e presença da Polícia Militar ou de representantes de outras instâncias / órgãos da Segurança Pública, justamente pelo fato de que os agentes estão na atividade empírica constante, na experiência do contato direto com a população, investigando os fenômenos sociais e diversas situações de evolução da criminalidades e outros aspectos sociais a partir da Segurança comunitária.

Neste sentido, os policiais são, também, fontes ricas de conselhos, orientações, dados estatísticos, que podem conduzir investigações sociais e legitimar, com os demais membros dos Conselhos, diretrizes e políticas pública que 
redirecionem a ótica dos planejamentos estratégicos de organização social. A presença da Polícia Militar e outros órgãos do setor, são essenciais. Há muitas experiências pelo Brasil que apontam esta especificidade de representação, com êxito.

É o caso do PROERD (Programa Educacional de Resistência às Drogas e à Violência), que tem como objetivo levar a Policia Militar às escolas e comunidades, para um estreitamento dialógico de formação humana, através de orientações, palestras, distribuição de materiais didáticos específicos, atividades artísticas de integração e socialização, fomentando o interesse dos alunos aos temas que envolvem prevenção às drogas, violência, assédios, e como ser um bom cidadão colaborativo na comunidade. Este é um projeto premiado no país e que envolve justamente esta relação polícia/comunidade. Mas, há outros diversos, que se acoplam nesta missão de ampliação dos ecossistemas comunicacionais / dialógicos com a população.

Portanto, seja na presença e ação direta da polícia nos bairros ou na contribuição à articulação de diretrizes e políticas públicas nos Conselhos Comunitários, a polícia é personagem estratégico para o bom desenvolvimento da população. E é neste sentido que as representações sociais se operam. Sabemos que em razão dos enfrentamentos há no senso comum, em muitos casos, imagens negativas da presença da polícia nos territórios comunitários. Não é uma tarefa fácil o enfrentamento dos crime organizado que historicamente, em muitos casos, estão alocados em determinados territórios / bairros. Por isso, além da ação ostensiva é preciso criar mecanismos dialógicos que mostrem à população que a polícia é parceria afirmativa do desejo de construção de uma cultura de paz e proteção.

A representação social é uma importante área de pesquisa que engloba o estado de pertencimento dos sujeitos sociais em um determinado cenário, construindo, de forma coletiva e democrática o discurso de integração de sentidos, perspectivas, soluções. Conforme diz Jodelet (1989), "as representações sociais devem ser estudadas articulando elementos afetivos, mentais, sociais, integrando a cognição, a linguagem e a comunicação às relações sociais que afetam as representações sociais e à realidade material, social e ideativa sobre a qual elas intervêm". Portanto, como aponta a autora, a estrutura de imagem dos agentes da segurança pública - suas ações, discursos e pertencimento no espaço social -, constrói-se a participação da operação 
dos sentidos, pois a comunidade, através da sensação de proteção, encurtamento das distâncias e eliminação do status de medo que o discurso do senso comum foi se perpetrando ao longo do tempo, ela garante o sentido de aproximação e confiança.

Aliás, esta é uma palavra muito importante na construção do estado social dialógico: a confiança. Obviamente que há muitos casos de excessos, por parte de muitos agentes da segurança pública que deveriam estar cumprindo a missão constitucional da garantia da ordem e da proteção social, noticiados na imprensa e rigorosamente investigados e punidos pelo sistema da justiça, através das corregedorias. Mas, casos de erros e excessos de uns, não devem tomar o estado do sentido de todos. Isso é um erro clássico detectado em análises de discursos de senso comum.

É por isso que a comunicação, a construção do espaço para o diálogo ampliado e a inserção destes agentes na construção e condução das comunidades são importantes para a definição de um novo ambiente calcado em democratização dialógica. Essa participação, esta presença mais contínua do agente de segurança na vida da população, do bairro, acaba gerando este senso de confiança, tão necessária na relação polícia/comunidade. Aliás, a própria análise de discurso (que também é um campo de interpretação dos sentidos dos fenômenos e das relações sociais, da representação) aponta a importância de ampliar situações, parcerias, projetos, que minimizem o espectro negativo da relação polícia/comunidade, direcionando, assim, um estado social de construção efetiva.

No que tange aos estudos das representações sociais (importante fundamentação teórica para este constructo reflexivo) dois aspectos são relevantes para tecer esta fundamentação epistemológica. A primeira, a percepção sobre o relacionamento entre indivídio/sociedade, que busca posicionamento integrador e age diretamente no âmbito da construção e dos embates das subjetividades; segundo, ao abrir espaço para a percepção do estado social dos atores envolvidos, ao abrir espaço para a construção da subjetividade, também opera, portanto, a discussão sobre a questão do afeto, tão necessário nesta nossa discussão sobre a presença da polícia nos diversos espaços de integração social/comunitário. Os afetos são expressões cognitivas que se constroem no embate com o outro, no diálogo e na presença do outro. É neste viés que se opera os estudos de representações sociais aportados no 
entendimento da presença estratégica de agentes da segurança pública, entre os quais a polícia militar, inserido na vida cotidiana da população.

O estado de pertencimento, de presença normalizada, de sentidos de afetos, de confiança e contribuições discursivas e operacionais (como ocorre, por exemplo, na presença dos mesmo em Conselhos Comunitários, anteriormente citados), estabelece a reação de construção de uma relação afirmativa. Este é o objeto deste artigo. A comunicação, que falaremos mais a seguir, ela se perpetua em diversas manifestações. Não é expressa apenas no diálogo verbal, mas, em formas e vieses que concretizam um estado de aproximação e pertencimento. Ao dispor refletir sobre o papel do policial e demais agentes de segurança pública neste constructo com a comunidade, se legitima um desejo de pensar sobre formas e métodos, planos e ações, que descontruam o negativismo históricos de estrutura de imagem/relação entre estes servidores públicos da segurança e a população.

Por isso, ações educativas, de políticas públicas, culturais, esportivas, de qualidade vida, de cidadania e expressão dos sentidos positivos, são buscas constantes dos que pensam em legitimação de espaço social democrático. A fundamentação teoria que dá aporte este pensamento, aqui refletivo, perpassa pela comunicação e pelas representações sociais estruturadas.

Neste sentido, podemos tecer quatro aspectos que são consideradas essenciais para o desenvolvimento do policiamento comunitário:

I) A organização da prevenção do crime tendo como base a comunicação ampliada com a comunidade, o que alguns autores chamam de ecossistemas comunicacionais democráticos nos espaços de integração, construção e socialização das subjetividades;

2) A reorientação das atividades de policiamento para enfatizar os serviços não emergenciais e para organizar e mobilizar a comunidade para participar da prevenção do crime, tecendo, portanto, uma parceria afirmativa entre os agentes de segurança e a população, que passa a ser partícipe do processo de mobilização de diretrizes e políticas públicas com foco na segurança;

3) A articulação de projetos e propostas que perpassem por setores como educação, cultura, esporte, articulação política, como são os casos, por exemplo, de projetos exitosos como programas como o Proerd - entre outros - ;

4) A participação de pessoas civis, não-policiais, no planejamento, execução, monitoramento e/ou avaliação das atividades de segurança pública, como é o caso, por exemplo, dos Conselhos Comunitários. 
Faz-se necessário destacar, também, que estas operações que buscam a ampliação da presença dos policiais e demais atores da segurança pública nas comunidades, em diálogos permanentes com os diversos setores sociais, perpassam pela operacionalização que, por vezes, pode encontrar, também, desafios e dificuldades. É importantes destacar algumas: a) o investimento - econômico e de incentivos - à esta prática estratégica de conexão com os bairros e comunidades; b) a capacitação continuada, formação dos agentes sobre os aspectos dialógicos e históricos que podem ser barreiras para a conexão ampliada nestes cenários; c) o planejamento policial, com foco nas operações humanizadas com o intuito de acoplar, com eficiência, as contribuições/participações da própria comunidade nas operações de combate ao crime organizado, violência e desordem; d) possíveis problemáticas de ótica de operações ostensivas contra o crime, surgidas na relação polícia e outros setores/organismo públicos.

É possível articular as demandas estratégicas para o sustento do discurso e da ação do policiamento nas comunidades. Para isso, também é preciso pensar em alguns aspectos que se fazem necessários: a) a importância do fortalecimento das políticas públicas nas áreas econômica, social e cultural, particularmente na área da educação e na geração de emprego e renda; b) a redução da impunidade através de mudanças na legislação e do aperfeiçoamento da atuação das organizações dos sistemas de segurança pública e justiça criminal; c) o trabalho continuo, junto aos setores da comunicação social, imprensa e demais mecanismos de informação para ampliar a estrutura de imagem dos trabalhos de proteção realizados pelos agentes de segurança e a comunidade.

\section{O PAPEL DA COMUNICAÇÃO NESTA CONSTRUÇÃO}

O trabalho do policiamento é uma estratégica necessária e importante para a manutenção da ordem social, da proteção coletiva, do cumprimento constitucional, mas, isoladamente, tem efeito limitador e beira a situações de conflitos diversos. $\mathrm{O}$ policiamento comunitário é considerado um tipo de policiamento capaz de contribuir para a melhoria da segurança pública, principalmente quando promover a integração 
de esforços da polícia e da comunidade no desenvolvimento de programas de prevenção do crime e gestão local da segurança pública.

Neste viés, faz-se necessário destacar que o policiamento comunitário tem um foco maior no âmbito das estratégias de prevenção e não apenas parra o atendimento de ocorrências, conflitos e combates. Neste caso, o policiamento comunitário promove a integração dos esforços da polícia e da comunidade na tentativa de eliminar as causas da violência, estabelecendo um diálogo ampliado, uma presença mais afirmativa - gerando mais confiança e respeito -. Este sistema integra a polícia e a comunidade, inclusive, na proposição de diretrizes e definição de prioridades calcados, também, na articulação de políticas públicas, em relação à prevenção criminal. Portanto, a comunicação é um elemento essencial para este ímpeto, perpetrando, neste tipo de policiamento o comunitário - um aumento da segurança e da motivação dos policiais e dos membros da comunidade no enfretamento da criminalidade. Esta intersecção de atores sociais e estratégias contribuem para a afirmação da estrutura de imagem e de representação social dos policiais na comunidade, inclusive, fomentando diminuição da violência, do crime organizado, estabelecendo um status sociais diferenciado.

Estamos refletindo, aqui, sobre o aumento da confiança, a aproximação com a população, a contribuição das vertentes de fomentos de diretrizes estabelecidas sobre o universo da política pública e aumento da sensação de segurança. $O$ policiamento comunitário, com base nestes referenciais os quais apontamos, se opera como uma filosofia e estratégia organizacional/ operacional bastante afirmativa. Seu referencial histórico datam dos anos de 1990 e, com o passar do tempo, as experiências e inserções tornaram-se ainda mais afirmativas.

Essas mudanças organizacionais e operacionais, particularmente no seu relacionamento com a sociedade, visa dar respostas a novas expectativas da sociedade e integrar esforços da polícia e da sociedade na direção de objetivos comuns, como, por exemplo, o cumprimento de direitos garantidos, a proteção social, o diálogo respeitoso e de gratidão aos que empenham, em muitos casos, a própria vida em detrimento da proteção do outro. 
É preciso pensar este viés no campo da comunicação. Esta é uma área essencial para acoplar aos intentos dos agentes de segurança pública no âmbito da relação com a comunidade. Isso se faz necessário perceber pelo fato de que há iniciativas diversas de comunicação social no universo laboral da polícia, inclusive, com diretrizes especificas e setores de contato funcionalista com a imprensa, atuando no encaminhamento de releases, notícias, agendamentos de entrevistas na imprensa clássica, entre outras funções. Mas a comunicação acaba saltando estas esferas funcionais, quando atrelado ao sentido da comunicação dialógica, o que foi citado anteriormente como ecossistemas comunicacionais abertos e democráticos. Neste sentido, se opera o contexto do diálogo em espaços diversos e com atores diversos das comunidades.

É este tipo de comunicação em que o policiamento comunitário também atua, já que prega conceitos de aproximação enriquecida com as populações dos bairros diversos que compõem uma comunidade, bem como, aproximação enriquecida com atores de outras agências de socialização (como a de gestores políticos, sociais, religiosos, culturais, educativos, e outros). Portanto, a construção coletiva da comunidade, quando pensada sob o viés do espectro da segurança pública, conta com o policiamento presente, numa constância de representação social, de identidade e de sentidos.

\section{CONCLUSÃO}

O que se operou nesta breve reflexão é que há uma disposição dos agentes de segurança pública em fomentar diretrizes de parcerias entre a polícia e a comunidade. Esta não é uma ação inovadora, que nunca ocorreu. Pelo contrário. As experiências de policiamento comunitário datam de 1980 no Brasil e buscam tecer alternativas diversas que aproximem este setor público tão importante para a garantia dos direitos da população - especialmente o direito de ser protegido pelo estado -

Nesta reflexão aportada neste artigo, buscou-se apontar, com o subsídio de referenciais teóricos, o conceito de representação social, identidade, participação coletiva e construtos estratégicos de presença do policial nas comunidades, articulando, através de projetos, programas, inciativas educativas, culturais e 
esportivas, de mobilização comunitária, de orientação cidadã, de práticas de integração e socialização, uma cultura de paz, aportada na participação da comunidade no fomento de estratégias contra o crime, a violência, as drogas, as práticas erradas.

O presente trabalho se faz útil para pensar a comunicação e a representação social como forma de trabalhar a estruturação de imagem dos policiais e organismos de segurança pública que, muitas vezes, é visto de forma negativa ou desconstruída em razão de situações erros de alguns. O coletivo dos atores da segurança pública precisam estar numa relação ampliada com a comunidade, gerando confiança, respeito, práticas de orientação, desenvolvimento e proteção. São estes agentes que, em muitos casos, enfrentam situações de pleno estresse e perigo à própria vida, em atendimento à constituição e ao dever. Portanto, o policiamento comunitário é uma alternativa louvável e eficaz para a aproximação dos policiais - e demais agentes da segurança pública - com a população.

\section{REFERENCIAL BIBLIOGRÁFICO}

JODELET, D., 1985. La representación social: Fenómenos, concepto y teoría. In: Psicologia Social (S. Moscovici, org.), pp. 469-494, Barcelona: Paídos.

, 1989a. Représentations sociales: un do-main en expansion. In: Les Représentations Sociales (D. Jodelet, org.), pp. 31-61, Paris: Presses Universitaires de France.

MESQUITA NETO, P. de. Policiamento Comunitário: a experiência em São Paulo. Revista Brasileira de Ciências Criminais, São Paulo, Instituto Brasileiro de Ciências Criminais, ano 7, n.25, p.281-292, jan./mar. 1999.

MESQUITA NETO, P. de.; AFFONSO, B. Policiamento Comunitário: a experiência em São Paulo. São Paulo: Núcleo de Estudos da Violência da Universidade de São Paulo, 1998. Manuscrito. 
PMSP. Polícia Militar do Estado de São Paulo. Projeto Polícia Comunitária: implantação de modelo e ação educativa. São Paulo: PMSP, Conselho Geral da Comunidade, 1993. 